CASE REPORT

\title{
JOINT RUPTURE FOLLOWING INTERNAL DERANGEMENT OF THE KNEE
}

\author{
M. A. STODELL, MB, MRCP
}

Senior Registrar in Rheumatology, Westminster Hospital, S.W.1

The importance of recognising acute rupture of the knee joint is now realised. It was described in patients with rheumatoid arthritis, by Dixon and Grant (1964). There are also many reports describing its occurrence in osteoarthritis. More recently sporadic cases are being documented where the lesion occurred in a previously normal joint, Good and Pozderac (1977).

I report a patient with an arthrographically proven capsular rupture following a presumed internal derangement of the knee.

\section{CASE REPORT}

While playing rugby a 22 year old man sustained a rotational injury during flexion, to his left knee. Before this event, to his knowledge, his knee had been normal; and there was no clinical evidence of arthritis. That evening he noticed his knee had become painful and swollen. One week later, after going for a swim (crawl stroke), he found that the swelling in his knee had lessened and he had developed a swollen calf. Shortly after he was seen at this hospital where he was found to have an effusion in the knee, swelling and pitting oedema of the calf and ankle. There was no popliteal cyst to be felt or other clinical abnormality in the knee joint. No bruising was evident around the lower leg. Twenty $\mathrm{mls}$. of straw-coloured fluid were aspirated and an arthrogram performed. This revealed the leak of contrast from the posterior part of the capsule into the calf.

He was seen five weeks later, when his only complaint was of occassional clicking in the knee. On examination the swelling in his calf had disappeared and there were no abnormal signs in his knee joint.

\section{DISCUSSION}

In one series of 82 patients presenting with a popliteal cyst, $\mathbf{4 0}$ patients were found to have osteoarthritis, 27 rheumatoid arthritis, four an "injury of cartilage" and the remainder with a number of other rarer conditions, Burleson et al (1956). The incidence of popliteal cysts noted in various disorders obviously depends on the groups of patients one is seeing. This also applies to those presenting with acute capsular rupture. The mechanism of development of popliteal cysts has been demonstrated, Jayson and Dixon (1970b). These authors found that the development of the cyst limited the

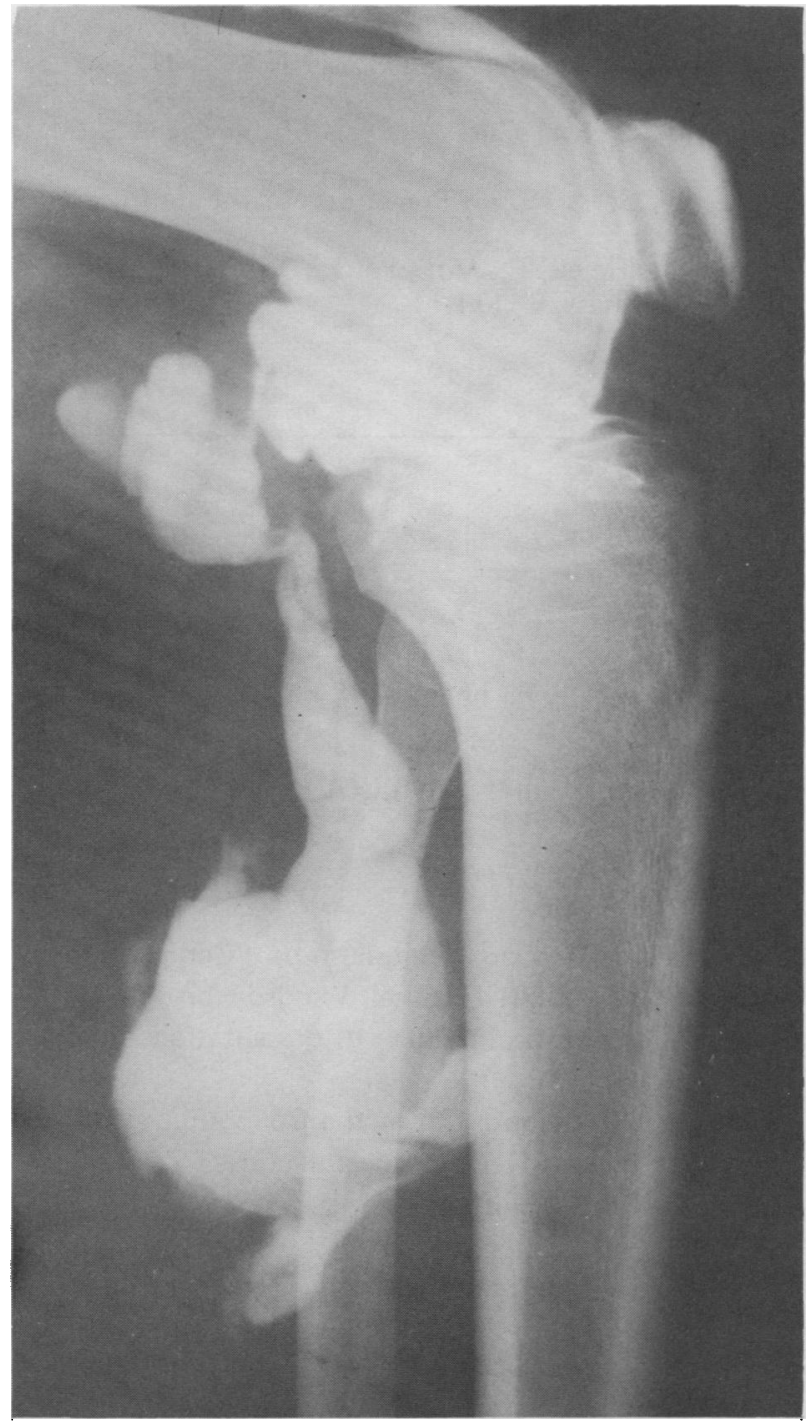

intra-articular pressure rise during joint use. Jayson and Dixon (1970a) found in the experimental situation that increasing effusion volumes produced acute joint rupture only in control or early involved knees of rheumatoid arthritis. It is thought that in these instances the synovial wall has not been strengthened by progressive fibrosis (as 
in the case in chronic rheumatoid arthritis). Despite this it is interesting to speculate why acute joint rupture is seen so infrequently in effusions following an internal derangement of the knee.

In the patient described above it must be conceded that the diagnosis has not been confirmed arthroscopically, but nevertheless, it is most unusual for a previously normal knee joint to rupture following a post-traumatic effusion.

\section{ACKNOWLEDGEMENTS}

I would like to thank Dr. Ian Curwen for permission to report this case and Dr. Mark Downes for performing the arthrogram.

\section{REFERENCES}

Burleson, R. J., Bickel, W. H. and Dahlin, D. C. 1956. "Popliteal cyst. A Clinicopathological Survey." J.Bone Jt.Surg. 38A: 1256-1274.

Dixon, A. St. J. and Grant, C. 1964. "Acute synovial rupture in rheumatoid arthritis. Clinical and experimental observations." Lancet i: 742-745.

Good, A. E. and Pozderac, R. V. 1977. "Ecchymosis of the lower leg. A sign of haemarthrosis with synovial rupture." Arthritis and Rheum. 20: 1009-1013.

Jayson, M. I. V. and Dixon, A. St. J. 1970a. "Intra-articular pressure in rheumatoid arthritis of the knee. III Pressure changes during joint use." Ann. Rheum.Dis. 29: 401-408.

Jayson M. E. V. and Dixon, A. St. J. 1970b. "Valvular mechanisms in juxta-articular cysts." Ann.Rheum.Dis. 29: 415-420.

\section{CARDIAC PATIENTS - SPORTS MEDICINE WHEN AN EXERCISE PROGRAMME IS INDICATED}

\section{A RELIABLE ACCURATE AND CONVENIENT WAY TO} MONITOR HEART RATE

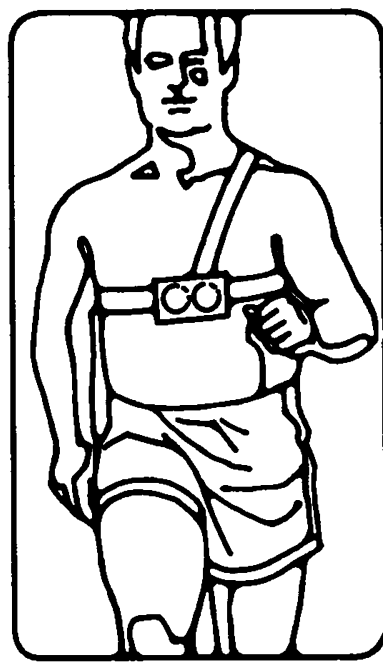

EXERSENTRY provides an ideal way to adhere to an exercise programme, providing immediate, continuous, unobtrusive feedback when required to raise the heart rate to a prescribed level for a standard length of time. Size 4 " $\times 2 \frac{1}{2}$ " $\times 1 "$, weight $3 \mathrm{oz}$ it is worn conveniently presenting no obstacles to movement. The electrodes are built into a lightweight belt worn around the chest. No paste is required. Dial in High/Low settings between 50 to 200 BPM and EXERSENTRY will automatically alarm, with high tone or low tone if the heart rate falls outside the prescribed range. A digital display continuously shows heart rate BPM from 40 to over 210 BPM. A target heart rate range as narrow as 10 beats per minute or as wide as desired can be programmed. Lamp blinks to show each heart beat. Advanced automatic sensitivity to adapt to each users heartbeat within seconds. Power: $1-1.5$ AAA battery good for about a year. Rugged impact resistant plastic case. High quality microelectronic technology. Optional accessories: cycle/treadmill bracket fitting with extension electrodes lead and electrode belt.

STEPYENS RO. Medical Electronics, 41/BJ5, Dickson Rd., Blackpool, U.K. Tel. 0253-23755
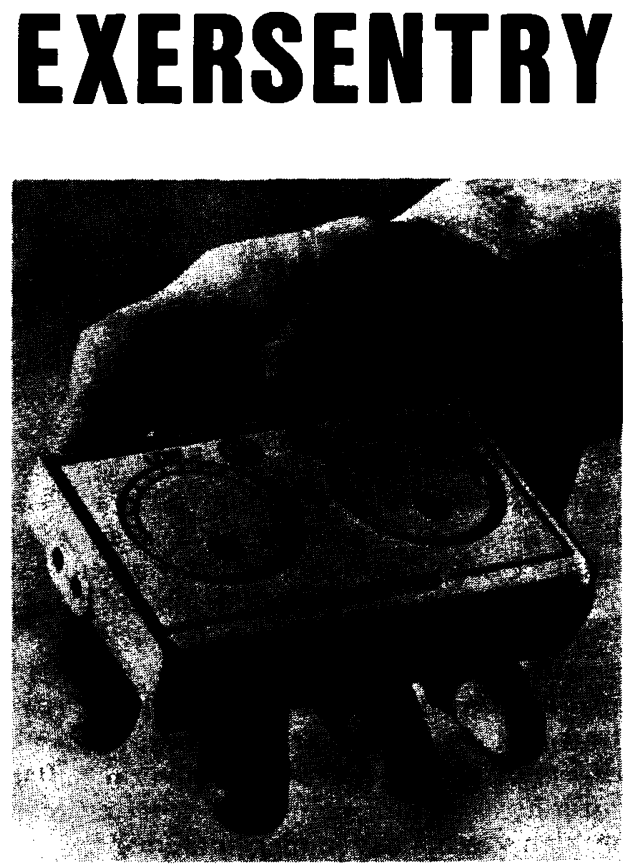

PRICE: $£ 166.00$ sterling

(U.K. plus VAT) 